\title{
RESTRIÇÕES À POSIÇÃO DE SPREPS TEMPORAIS NA MODALIDADE FALADA
}

\author{
Maria da Conceição de PAIVA*
}

- RESUMO: Diversos estudos sobre ordem de palavras atestam a importância do princípio peso final, segundo o qual constituintes mais pesados se situam na posição final da oração. Neste artigo, trazemos algumas evidências de que esse princípio explica a posição variável de sintagmas preposicionais temporais no português brasileiro falado. A ordem desses constituintes é analisada sob duas perspectivas: consideramos, inicialmente, sentenças que contêm apenas o Sprep temporal em diferentes posições; num segundo momento, estendemos a análise às sentenças em que Spreps temporais pós-verbais coocorrem com circunstanciais de lugar e de modo. Por meio de uma análise quantitativa, mensuramos o efeito da variável extensão do Sprep temporal, considerada em termos de número de palavras, sobre a posição que esse constituinte ocupa na oração. A análise mostra que o efeito do princípio peso final (end weight) é particularmente notável nas orações em que o Sprep temporal coocorre com outros circunstanciais, como os de lugar e de modo, superando restrições de natureza sintática e semântica.

- PALAVRAS- CHAVE: Spreps temporais. Posição. Variação. Peso.

\section{Introdução}

A maioria das gramáticas do português (ver, por exemplo, CUNHA, 1976) assumem uma restrição à ordenação de circunstanciais que codificam as categorias de tempo e de lugar ao destacar que esses constituintes satélites são pospostos aos constituintes argumentais, situando-se, mais frequentemente, na margem direita da oração. Evidências tanto da modalidade falada como da modalidade escrita permitem constatar, no entanto, um amplo espectro de variação na posição dos sintagmas preposicionais temporais, como mostram os exemplos de (1) a (4):

a- na margem esquerda da oração

(1) "Depois da pelada a gente faz uma fofoca." - Fala, Amostra Censo 1980, fal. 02.

b- na margem direita da oração

(2) "Chegamos lá no dia vinte e seis de julho." -Fala, Amostra Censo 1980, fal. 46.

* UFRJ - Universidade Federal do Rio de Janeiro. Rio de Janeiro - RJ - Brasil. 21.941-917 - paiva@club-internet.fr 
C- entre verbo e sujeito

(3) "Os números, nos quatro primeiros meses de cada ano," tiveram pouca variação. - Escrita, Jornal Extra.

d- entre verbo e complemento

(4) "Vamos poder ver, na próxima legislatura, se a reforma tributária não saiu no governo FHC por falta de consenso." - Escrita, Jornal O Globo.

Evidentemente, essas diferentes possibilidades se distribuem de forma bastante desequilibrada no uso linguístico (PAIVA 2008a; PAIVA et al., 2007) e envolve a coatuação de diferentes parâmetros que colaboram para que determinadas posições sejam mais recorrentes do que outras. Diversos trabalhos destacam restrições impostas pela própria categoria dêitica codificada (tempo, modo, espaço), pelo significado do circunstancial, pela sua função sintática e pela sua função discursiva, pelo grau de transitividade da oração em que o circunstancial está inserido (MARTELOTA, 1994; SHAER, 2004; CEZÁRIO et al., 2004; CEZÁRIO; ANDRADE; FREITAS, 2005; CEZÁRIO; SÁ; COSTA, 2005; FREITAS, 2001; COSTA, 2004; BRASIL 2005; ANDRADE, 2005; GOMES, 2006; PAIVA, 2008a; PAIVA et al., 2007; LESSA, 2007; SÁ, 2009). A posição desses constituintes satélite envolve, ainda, restrições ligadas ao peso ou extensão do sintagma preposicional (BRASIL, 2005; ANDRADE, 2005; SÁ, 2009; COSTA, 2004), refletindo, também, propriedades dos diferentes gêneros textuais (PAIVA et al., 2007).

A natureza multifatorial da variação na ordem dos circunstanciais se investe de maior importância, na medida em que os diferentes parâmetros que a controlam podem decorrer de princípios que conflitem entre si. Os princípios sintáticos como os que regem a relação de interdependência entre o verbo e seus argumentos (princípio de coesão ou de inerência), o princípio de centralidade semântica da categoria circunstancial e princípios ligados à extensão dos constituintes operam simultaneamente sobre a posição desses constituintes. Neste artigo, nos debruçamos sobre essa questão retomando mais especificamente a variabilidade na posição dos Spreps temporais na modalidade falada sob o prisma do denominado princípio de peso final (end weight), proposto por Quirk et al. (1985) e discutido, dentre outros, por Gries (2003), Hawkins (1994, 2000, 2001), Wasow (1997, 2002), Lohse; Hawkins e Wasow (2004). Segundo esse princípio, uma parte considerável da variação na ordem de constituintes oracionais, principalmente dos que se situam após o núcleo verbal, pode ser explicada em termos da sua extensão ou complexidade sintática. Prevê-se que constituintes menores e menos complexos precedem constituintes maiores e mais complexos, ou, em outros termos, que a periferia direita da oração é o site preferencial de constituintes mais pesados. $\mathrm{O}$ efeito 
desse princípio sobre a posição variável dos Spreps temporais é contraposto a princípios de natureza semântica e de natureza sintática.

A correlação entre a posição e extensão dos Spreps temporais é focalizada sob duas perspectivas. Num primeiro momento, verificamos a relevância do princípio peso final em orações que contêm apenas um constituinte satélite, no caso, um Sprep temporal em diferentes posições. Assumimos, como ponto de partida, que, nessas orações, a extensão do constituinte temporal permite explicar, dentre outros aspectos, sua oscilação entre as margens da oração e sua resistência às posições internas, principalmente àquelas que acarretam rupturas entre o verbo e seus argumentos.

Num segundo momento, focalizamos orações em que os Spreps temporais coocorrem com circunstanciais de lugar ou de modo, com o intuito de verificar em que medida a coexistência de categorias semânticas distintas interfere com o princípio peso final. Nesse ponto, estendemos a análise à sequenciação relativa de categoria semânticas distintas de circunstanciais, buscando contrapor o efeito de um princípio ligado à extensão ao de princípios ligados, por um lado, à centralidade da categoria semântica e, por outro, às relações de dependência sintática entre o constituinte circunstancial e o verbo. Através dessa análise, trazemos evidências para a generalidade e maior adequação do princípio peso final e comprovamos a necessidade de controlar a extensão de outros constituintes satélite que co-ocorrem com o Sprep temporal.

Os dados em análise foram coletados em 15 entrevistas sociolinguísticas que compõem a amostra Censo 1980, constituída no período de 1980 a 1984. ${ }^{1}$ Essa amostra possui características de discurso semi-informal, permitindo, assim, extrair algumas conclusões acerca da aplicabilidade do princípio de extensão em situações comunicativas que, se não são completamente espontâneas, estão sujeitas a menor monitoramento.

Este artigo está organizado da seguinte forma: na seção 1, retomamos o princípio de extensão e sua aplicabilidade a diferentes fenômenos de ordenação de constituintes; na seção 2, focalizamos o efeito desse princípio em orações com um único circunstancial temporal e, na seção 3, mostramos sua generalização para orações em que circunstanciais de tempo co-ocorrem com circuntanciais de tempo e/ou de modo. A sequenciação relativa dessas categorias é focalizada na quinta seção. Seguem-se as conclusões e as referências.

\footnotetext{
A amostra Censo, constituída pelos pesquisadores do Grupo PEUL (Programa de Estudos do Uso da Língua) é composta de 64 entrevistas com falantes cariocas e foi estratificada de acordo com as variáveis gênero, idade e escolaridade. Encontra-se disponível no endereço: <http://www.letras.ufrj.br/peul>.
} 


\section{Restrições ligadas ao peso/extensão dos constituintes}

A correlação entre ordem e peso/extensão dos constituintes da oração tem recebido diferentes formulações que procuram explicar principalmente a disposição linear variável de diversos constituintes pós-verbais. Quirk et ali (1985), por exemplo, traduzem essa correlação no princípio denominado peso final (end-weight) que impõe restrições à disposição sintagmática de SN's e Spreps ligados ao mesmo núcleo verbal. De acordo com esse princípio, em sequências de dois constituintes de extensão diferente, o menor precede o maior. ${ }^{2}$ Esse princípio explica de forma satisfatória variações de disposição sintagmática, como a alternância entre V- SN SPrep vs V Sprep SN - dative alternation, ver Wasow (1997), Wasow e Arnold (2003), Abeillé e Godard (2006) -, a separação entre preposição e verbo nas construções verbo-partícula do inglês (WASOW; ARNOLD, 2003; GRIES, 2003; LOHSE; HAWKINS; WASOW, 2004), a posição do sintagma adjetival (ABEILLÉ; GODARD, 2006), a variação na ordem de sintagmas preposicionais argumentais e não argumentais (HAWKINS, 1994, 1998, 2003; NIV, 1992; SIEWIERSKA, 1993; ABEILLÉ; GODARD, 2006).

Como salienta Quirk et al. (1985), o princípio de peso final (end weight) não pode ser entendido como um primitivo. Ele está correlacionado à forma de embalagem da informação, refletindo uma tendência de organização discursiva segundo a qual material linguístico com maior conteúdo informativo tende a seguir material com menor conteúdo informativo. Relaciona-se ainda com a tendência a posicionar no final da oração o material mais importante (foco). Essa interdependência entre aspectos de níveis distintos permite discutir a própria independência do princípio end weight como colocam Wasow e Arnold (2003), para quem:

[...] one would expect that length and newness of information would tend to correlate. And this raises the question of whether weight and information structure are two distinct factors influencing ordering, or whether one of them only looks like a causal factor because of its high correlation with the other one.

Em muitos aspectos, essa formulação encontra paralelo nos subprincípios de quantidade e de ordenação linear, propostos por Givón (1995, 2001). Segundo o princípio da quantidade, uma informação maior, menos previsível requer codificação por material linguístico mais extenso. O princípio da ordenação linear, por sua vez, prevê que informação mais previsível seja colocada em primeiro lugar

Hawkins $(1994,2000)$ alerta, no entanto, que esse princípio se aplica às línguas do tipo verbo inicial. Em algumas línguas do tipo verbo final, observa-se uma tendência contrária, com elementos maiores precedendo elementos menores - ver também Shannon e Coffey (2004). 
na cadeia linguística. Associando-se os dois subprincípios, pode-se supor que a informação menos previsível, mais extensa, seja preferencialmente situada após a informação mais previsível ${ }^{3}$.

Essa via se mostra particularmente frutífera no que se refere à variabilidade sintagmática dos sintagmas preposicionais circunstanciais. Como já mostraram diversos trabalhos (VOTRE; SANTOS, 1984; NIV, 1992; ABEILLÉ; GODARD, 2006; BRASIL, 2005; ANDRADE, 2005; CEZÁRIO; ANDRADE; FREITAS, 2005; PAIVA et al., 2009), a posição de diferentes classes de constituintes adverbiais (modo, intensidade, lugar, tempo) se submete, em diferentes línguas, a restrições impostas pelo seu peso ou extensão. Destaque-se, no entanto, que, na sua maioria, essas análises mensuram apenas o peso do constituinte circunstancial, principalmente dos que se situam nas periferias esquerda e direita da oração sem considerar a extensão de outros constituintes, argumentais ou não argumentais, presentes na oração.

A correlação entre posição e peso de constituintes circunstanciais tem recebido maior atenção no que se refere aos advérbios. Assim, Niv (1992) postula a existência de uma restrição à ocorrência de advérbios mais leves, principalmente os monossilábicos, após constituintes mais pesados (com 5 ou mais palavras) sejam eles argumentais ou não argumentais. Advérbios de menor extensão ocupam preferencialmente a posição inicial ou entre verbo e complemento, preservando, assim, o princípio de end weight. Advérbios mais longos, ao contrário, não se submetem a tal restrição, podendo ocorrer antes ou após constituintes mais pesados. Ainda que numa perspectiva teórica distinta, Abeillé e Godard (2006) admitem a mesma tendência para alguns advérbios do francês (como plus, jamais, bien) e a interpretam como o resultado de uma escala na forma de linearização de diversos constituintes ligados ao mesmo núcleo verbal (núcleo < leves < médios < pesados). Para o português europeu, Costa (2004) mostra que a posição à direita do verbo (entre verbo e objeto) pode ser ocupada, principalmente, por advérbios monossilábicos, que tendem a funcionar como elementos clíticos.

Duas questões subjazem necessariamente a qualquer formulação de um princípio relacionado ao peso dos constituintes. A primeira envolve uma certa superposição, sob certos aspectos inevitável, entre extensão e complexidade estrutural; a segunda se refere aos diferentes critérios utilizados na mensuração de extensão. A complexidade de um constituinte tem sido capturada mais frequentemente na diferença entre SN's não modificados por sintagmas preposicionais ou orações, a priori mais simples, em oposição a

Informação menos previsível, menos acessível pode ser situada no início da cadeia linguística em orações nas quais desempenha uma função de contraste. 
SN's acompanhados de Spreps ou de orações, em princípio, mais complexos. ${ }^{4}$ A extensão, por sua vez, tem sido mensurada através de critérios diferenciados como número de sílabas (GRIES, 2003; BRASIL, 2005), número de palavras (LOHSE; HAWKINS; WASOW, 2004; SÁ, 2009) ou mesmo número de fonemas. Como se pode esperar, os SPreps modificados, mais complexos são necessariamente mais extensos. Há evidências, no entanto, de que analisados separadamente, como o faz Wasow (2002), tanto o critério extensão como o critério complexidade são significativos para a ordem de constituintes.

O critério de mensuração da extensão em si mesmo parece ser menos relevante. Como mostram Wasow e Arnold (2003), na maioria das vezes, diversas medidas estão de tal forma relacionadas que se torna difícil escolher entre elas. Neste estudo, optamos por uma análise de peso em termos de extensão, mensurada através do número de palavras que constitui o Sprep, um critério que tem se mostrado eficaz para a análise do princípio de peso final

\section{Extensão e variabilidade sintagmática dos circunstanciais temporais}

As generalizações a respeito da correlação entre peso e ordem dos constituintes envolvem uma gradação que ultrapassa a oposição binária entre constituintes mais leves/constituintes mais pesados (WASOW, 1997). Assim, na análise da variabilidade posicional dos circunstanciais temporais, o número de palavras ${ }^{5}$ que constitui o Sprep foi codificado de acordo com a seguinte escala:

a- sintagma preposicional de 1 palavra.

(5) "Mas segunda-feira ele sai." - Fala, Amostra Censo 1980, fal. 07.

b-sintagma preposicional de 2 palavras

(6) "Aí, naquela epoca, ele me deu duzentos e cinquenta cruzeiro." - Fala, Amostra Censo 1980, fal.05.

C-sintagma preposicional de 3 a 4 palavras

(7) "Às dez hora tem que estar em casa." - Fala, Amostra Censo 1980, Fal. 05.

\footnotetext{
Hawkins $(1994,2000)$ propõe uma forma de mensuração em termos de domínio de reconhecimento, ou seja, de número de palavras necessárias para permitir o reconhecimento de todos os constituintes imediatos da oração. Baseado no pressuposto de que a linearização dos constituintes busca tornar o processamento mais fácil, o autor propõe um princípio que permite prever em línguas do tipo SVO "[...] a general preference for PP sequences whose IC-to-word ratios are as high as they can be: namely, those with short-before-long PPS." (HAWKINS, 2000, p.236).

5 Não entraremos aqui num detalhamento acerca do conceito de palavra ou dos critérios para considerar um elemento como tal. Na nossa análise, todos os elementos constituintes do Sprep foram computados independentemente da sua natureza.
} 
d- sintagma preposicional de 5 a 6 palavras

(8) O casamento começou as dez horas da manhã. - Fala, Amostra Censo 1980, fal. 47.

e- sintagma preposicional de 7 a 10 palavras

(9) "O meu pai chegou aqui, em mil novecentos e vinte e nove." - Fala, Amostra Censo 1980, fal. 43.

Inicialmente, convém observar a distribuição das posições exemplificadas de (1) a (4). A partir da análise de 442 Spreps temporais, coletados na amostra de 15 horas de gravação com falantes da variedade carioca, duas tendências complementares se destacam no gráfico 1: a) a marcada predominância dos Spreps temporais nas margens da oração; b) em consequência, a forte restrição desses constituintes em posições internas à oração, seja entre $\mathrm{S} \mathrm{e} \mathrm{V}$, seja entre $\mathrm{V}$ e O.

Gráfico 1 - Distribuição dos circunstanciais temporais de acordo com a posição

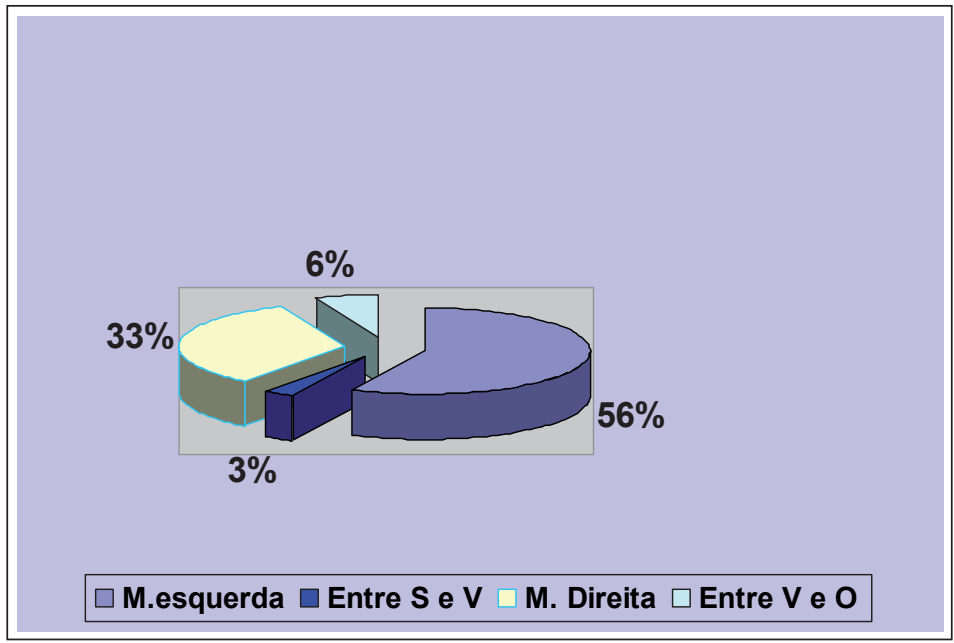

Fonte: elaboração própria.

A significativa recorrência de circunstanciais temporais nas margens da oração (89\%) confirma a tendência constatada em diversos estudos (MARTELOTTA, 1994; MACEDO; SANTANCHÉ, 1998; TARALLO et al., 1993; FREITAS, 2001; CEZÁRIO et al., 2004; CEZÁRIO; ANDRADE; FREITAS, 2005; CEZÁRIO; SÁ; COSTA, 2005; BRASIL, 2005; ANDRADE, 2005; LESSA, 2007; PAIVA et al., 2007; PAIVA, 2008a; SÁ, 2009). Ressalta, porém, a maior recorrência de Spreps temporais na margem esquerda da oração (56\%), um índice de que essa constitui, com base no critério de frequência, a posição não marcada (CROFT, 
1990; GIVÓN 1995) desses constituintes na modalidade falada. ${ }^{6}$ Evidentemente, como destacam Paiva et al. (2007) e Paiva (2008a), a predominância de Spreps temporais na periferia esquerda da oração reflete, em grande parte, as funções coesivas e segmentadoras desses constituintes, seja na retomada de informações já introduzidas (backward tie), seja para indexar o discurso subsequente, abrindo enquadres ou cenários temporais nos quais podem se inscrever diversos estados de coisas (forward tie).

A escassez de circunstanciais temporais em posições mediais, principalmente na adjacência esquerda do verbo (3\%), corrobora igualmente constatações de outros trabalhos (ver, além das referências anteriores, PAGOTTO, [199-17 e pode ser explicada como resultado do que Tomlin (1986) denomina um princípio de coesão, ou seja, uma tendência a evitar rupturas entre o verbo e seus argumentos. Uma restrição independente que pode ser generalizada a constituintes adverbiais de outras categorias semânticas, como os locativos (PAIVA, 2002; BRASIL 2005; GOMES, 2006; OLIVEIRA, 2004), qualitativos e modalizadores. (MORAES PINTO, 2002; MARTELOTTA; VLECK, 2007).

A oscilação dos Spreps temporais entre as margens esquerda e direita da oração, como mostramos a seguir, está correlacionada, de forma significativa, ao peso do circunstancial temporal. Uma contraparte natural do princípio end weight é a de que constituintes menores, menos pesados sejam preferencialmente posicionados na periferia esquerda da oração e os de maior peso se situem mais frequentemente na periferia direita. Nesse sentido, a variabilidade entre margem direita e margem esquerda não seria mais do que um outro resultado possível do princípio de peso final. Essa hipótese pode ser estendida às posições internas, pressupondo-se que constituintes adverbiais de menor extensão sejam mais facilmente autorizados em pontos de ruptura entre o verbo e seus argumentos do que constituintes mais extensos. (COSTA, 2004; GOMES, 2006). No entanto os resultados da tabela 1 validam apenas parcialmente essa hipótese.

\footnotetext{
No que se refere à posição dos circunstanciais temporais na escrita, os resultados são menos consistentes. Enquanto alguns estudos destacam a predominância dos temporais na margem esquerda (BRASIL, 2005; PAIVA, 2008b; PAIVA et al., 2007; CEZÁRIO; SÁ; COSTA, 2005), outros identificam uma acentuada flutuação entre margem esquerda e direita (ANDRADE, 2005; CEZÁRIO; ANDRADE; FREITAS, 2005; SÁ, 2009). É preciso considerar, no entanto, as diferenças de gênero dos textos utilizados em cada um desses trabalhos.

7 De acordo com Oliveira (2004), no português arcaico, essas posições eram produtivas para alguns advérbios como por exemplo aqui, e se reduzem, sensivelmente, no século XX. Segundo o estudo de Gomes (2006), a ocorrência de advérbios e Spreps temporais em posições internas à oração já era muito restrita no português brasileiro dos séculos XVIII e XIX.
} 
Tabela 1 - Posição e extensão do circunstancial (orações com 1 circunstancial)

\begin{tabular}{cccccc}
\hline Extensão & ME & S-V & MD & V-C & Total \\
\hline 1 & 5 & 0 & 4 & 2 & 11 \\
palavra & $45 \%$ & & $36 \%$ & $18 \%$ & \\
2 & 136 & 10 & 70 & 15 & 231 \\
palavras & $58 \%$ & $4 \%$ & $30 \%$ & $6 \%$ & \\
3 a 4 & 101 & 5 & 55 & 10 & 171 \\
palavras & $59 \%$ & $2 \%$ & $32 \%$ & $5 \%$ & 18 \\
5 a 6 & 6 & 0 & 10 & 2 & \\
palavras & $33 \%$ & & $55 \%$ & $11 \%$ & 11 \\
7 a 10 & 3 & 0 & 8 & 0 & \\
palavras & $27 \%$ & & $73 \%$ & & \\
\hline
\end{tabular}

Fonte: elaboração própria.

Confirmando as expectativas, os circunstanciais temporais de uma palavra apresentam índices mais expressivos para a margem esquerda (45\%) embora possam ocorrer, de forma significativa, na margem direita (36\%). Além disso, são escassos (18\%) na posição entre verbo e objeto e não ocorrem na fronteira entre sujeito e verbo. É possível que propriedades inerentes aos sintagmas preposicionais temporais de uma sílaba, normalmente Spreps sem cabeça, possam determinar algumas particularidades na sua disposição sintagmática.

Os Spreps temporais de 2 e os de 3 a 4 palavras, os mais recorrentes no corpus, tendem claramente a predominar na margem esquerda, com 58\% e $59 \%$, respectivamente, embora sejam igualmente susceptíveis de acentuada variabilidade. A hipótese colocada encontra evidências mais nítidas na distribuição de frequências para os sintagmas preposicionais temporais de maior extensão, para os quais se constata maior recorrência da margem direita: $55 \%$, para os Spreps de até 6 palavras e $72 \%$ para os Spreps de até 10 palavras.

Os resultados para as posições internas se conformam apenas em parte ao previsto na hipótese, em função do comportamento diferenciado das fronteiras entre sujeito e verbo e entre verbo e objeto, a primeira mais restritiva do que a segunda. Circunstanciais temporais são mais frequentes na posição entre verbo e complemento, com maior incidência dos menos extensos (2 palavras $=18 \%$ ). No entanto, contrariando as expectativas, mesmo Spreps mais extensos (de 5 a 6 palavras) podem se inserir nessa posição. É necessário considerar, no entanto, que as duas únicas ocorrências dessa configuração correspondem a objetos diretos oracionais, necessariamente mais extensos. 
As correlações depreendidas acima permitem afirmar que o princípio "peso final" explica uma parte considerável da posição variável dos Spreps temporais em orações com um único circunstancial.

\section{Orações com dois ou mais circunstanciais}

Uma questão relevante diz respeito à aplicação do princípio end weight a orações nas quais o circunstancial temporal coocorre com um outro satélite circunstancial. Visto que se destaca, na amostra analisada, a recorrência de oração com circunstanciais temporais e locativos (149 dados), concentraremo-nos, aqui, nessa combinação. Nessas orações, podem emergir diversas configurações sintagmáticas, envolvendo diferentes combinações entre posições periféricas e posições internas. A fim de operacionalizar a análise quantitativa, simplificamos essas possibilidades da seguinte forma:

a. dois circunstanciais na margem esquerda da oração.

(10) "Um dia, na festa, a gente se encontramos." - Fala, Amostra Censo 1980, fal. 02

b- dois circunstanciais na margem direita da oração.

(11) "Tinha um congresso em Porto Alegre logo no outro mês imediato, maio ou junho." - Fala, Amostra Censo 1980, fal. 32.

c- 1 circunstancial na margem esquerda e um na margem direita.

(12) " No início, ficou comigo na casa da minha mãe." - Amostra Censo 1980, fal. 42 .

d- 1 circunstancial na margem da oração (esquerda ou direita) e um em posição interna (entre $\mathrm{S}$ e $\mathrm{V}$ ou $\mathrm{V}$ e C).

(13) " Minha mãe, nesse tempo, morava na Ilha do governador, lá na Freguesia." - Amostra Censo 1980, fal. 42.

A distribuição dessas possibilidades aponta algumas alterações no que se refere à posição não marcada dos Spreps temporais, como mostram os resultados expostos no gráfico 2 : 
Gráfico 2 - Distribuição dos circunstanciais temporais de acordo com a posição

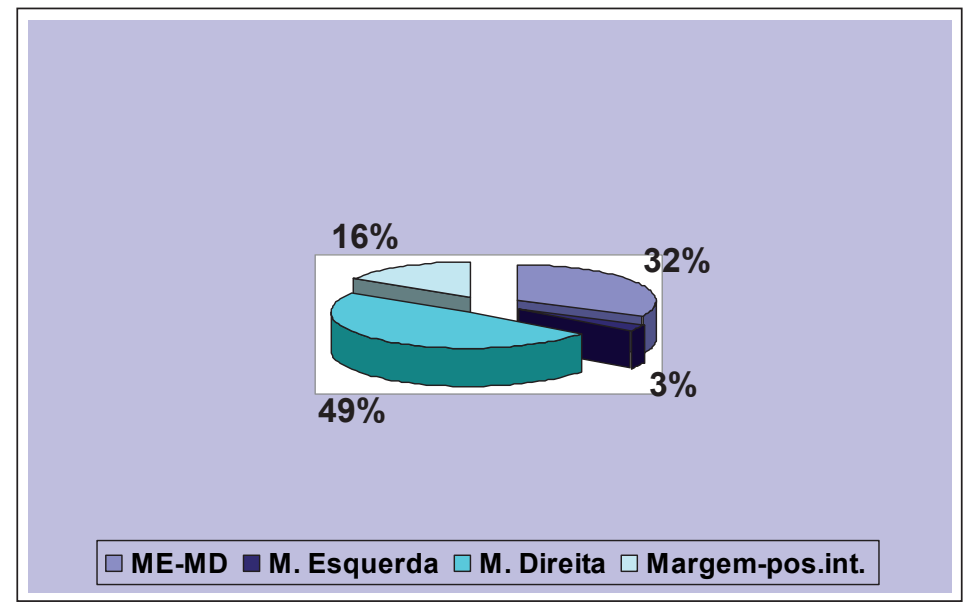

Fonte: elaboração própria.

Em orações nas quais o temporal coabita com um circunstancial locativo ou de modo, aumenta, de forma significativa, o índice associado à margem direita da oração (49\%), como no exemplo (11). Essa tendência é reforçada pela baixa frequência da configuração em que os dois circunstanciais se situam na margem esquerda, com apenas 3\%.

Mantém-se, no entanto, a tendência a posicionar esses constituintes em posições periféricas, com uma frequência de 32\% para ME/MD. Nesse último caso, verifica-se uma configuração conforme à ordem não marcada dos temporais que, via de regra, ocupam a margem esquerda da oração, deixando a margem direita para o outro circunstancial que com ele coabita, como ilustra o exemplo (12).

Um aspecto, que será retomado mais detalhadamente na próxima seção, emerge em alguns dos exemplos acima. No caso de o circunstancial locativo integrar a estrutura argumental do verbo com que se liga, interfere um princípio de adjacência que garante maior proximidade do constituinte circunstancial em relação a V.

Reitera-se igualmente a maior restrição às posições que rompem a adjacência entre o verbo e seus argumentos, com uma baixa frequência (16\%) da configuração em que um dos circunstanciais, geralmente o locativo, se situa em uma das margens da oração e o outro, mais frequentemente o temporal, na adjacência direita ou esquerda do núcleo verbal, como no exemplo (13).

A tabela 2 mostra, no entanto, que essa distribuição se relativiza de acordo com a extensão do circunstancial temporal. 
Tabela 2 - Posição dos circunstanciais temporais de acordo com extensão

\begin{tabular}{cccccc}
\hline & ME-MD & ME & MD & M-pos.int & Total \\
\hline 2 pal. & 34 & 5 & 51 & 13 & 103 \\
& $33 \%$ & $6 \%$ & $49 \%$ & $12 \%$ & \\
3-4 pal. & 20 & 1 & 26 & 13 & 60 \\
& $33 \%$ & $1 \%$ & $43 \%$ & $21 \%$ & 7 \\
5-6 pal. & 1 & 0 & 5 & 1 & \\
7-10 pal. & $14 \%$ & 0 & $72 \%$ & $14 \%$ & 2 \\
\hline
\end{tabular}

Fonte: elaboração própria.

Os circunstanciais temporais mais longos e mais pesados, acima de 5 palavras, são os mais propícios a se situarem, juntamente com o outro Sprep, na margem direita da oração (72\% e 100\%). Embora a distribuição muito desequilibrada dos dados não autorize conclusões definitivas, há indicações de que as predições autorizadas pelo princípio peso final (end weight) operam no sentido de evitar sequências de vários circunstanciais em outras posições, em especial na margem esquerda da oração. Essa tendência parece mais geral, atingindo igualmente Spreps temporais menos extensos, de até 4 palavras ou mesmo de 2 palavras, que, embora admitam variabilidade, tendem a se situar em posição final nas orações em que coocorrem com um outro Sprep.

A disponibilização das posições adjacentes ao verbo, principalmente entre o verbo e seu sujeito, é mais nítida para os constituintes temporais de 3 a 4 palavras. Predomina, nesse caso, a configuração em que o circunstancial locativo se posiciona na margem direita da oração, e o de tempo, em posição interna, como no já referido exemplo (13).

Embora esta análise se concentre nos sintagmas preposicionais, algumas evidências adicionais advêm das orações com advérbios, os elementos de menor extensão de acordo com o critério adotado para mensuração de peso. Exemplos como (14) mostram que os advérbios temporais mais leves são os que mais frequentemente se inserem na fronteira entre verbo e sujeito, confirmando tendência já identificada em outros trabalhos (COSTA, 2004; BRASIL, 2005; GOMES, 2006; NIV, 2005), situando-se o outro circunstancial, preferencialmente, na periferia direita da oração.

(14) “Cláudio Adão hoje está no Vasco." - Fala, Amostra Censo 1980, fal. 37. 
Há, portanto, indicações que autorizam a generalização do princípio peso final (end weigth) para orações em que os circunstanciais temporais coabitam com adjuntos de outras categorias como as de lugar.

\section{Peso e sequenciação relativa dos circunstanciais temporais}

Destacamos, na seção anterior, a recorrência da configuração estrutural em que dois constituintes satélite se situam na periferia direita da oração, ou seja, são pospostos ao núcleo verbal. Essa forma de ordenação suscita questões ligadas à sequenciação dos Spreps de distintas categorias semânticas, principalmente as de tempo, modo e lugar, igualmente variável, como mostram os exemplos (15) a (18):

\section{Lugar-tempo}

(15) "E eu comecei a trabalhar em oficina numa segunda-feira." - Fala, Amostra Censo 1980. fal. 46.

Tempo-lugar

(16) "Ela está com ideia de viajar agora em janeiro para Maceió." - Fala, Amostra Censo, fal. 42.

Tempo-modo

(17) "Não me lembro de ter ficado algum dia DE MAU HUMOR." - Fala, Amostra Censo 1980, fal. 42.

Modo-tempo

(18) "O time do Brasil jogou MUITO BEM nessa copa do mundo." - Fala, Amostra Censo 1980. fal. 40.

A análise da sequenciação dessas três categorias permite discutir uma questão central no que se refere a fenômenos multifatoriais, como a posição linear de constituintes da oração, qual seja, o possível conflito entre princípios de natureza distinta. No caso específico dos sintagmas preposicionais que expressam as categorias semânticas de tempo, lugar e modo, além de um princípio ligado ao peso do constituinte, coatuam restrições ligadas à centralidade da categoria semântica do circunstancial e restrições decorrentes da dependência sintática entre o Sprep e o verbo.

Uma primeira hipótese explicativa da variação ilustrada de (15) a (18) parte do princípio de que as categorias de tempo, modo e lugar se distribuem em uma hierarquia de centralidade semântica; a categoria de modo é mais central ao estado de coisas descrito, seguindo-se a categoria de lugar e, por fim, a categoria de tempo (modo > lugar > tempo). Essa hierarquia de centralidade 
traduzir-se-ia, em línguas do tipo verbo inicial, numa sequenciação categórica Sprep de modo - Sprep de lugar - Sprep de tempo (BOISSON, 1981; OUIRK et al., 1985). ${ }^{8}$

Subjaz a esse princípio um pressuposto mais geral de relação icônica entre integração semântica e ordem dos constituintes ou, nos termos de Bybee (1985), um princípio de distância icônica (iconic distance principle). A posição do constituinte na cadeia linear reflete o grau de dependência semântica entre o conteúdo por ele codificado e o elemento ao qual se liga. Na perspectiva de Givón (1995), conceitos cognitivamente mais integrados tendem a ser adjacentes na cadeia sintagmática, dado que a ativação de um deles desencadeia a ativação do outro (ver também HAIMAN, 1985).

Uma segunda hipótese explicativa das diversas formas de sequenciação de Spreps circunstanciais é a de que, independentemente da sua categoria semântica, os Spreps mais leves, menos extensos precedem os Spreps mais pesados, seguindo assim a restrição imposta pelo princípio peso final. A validade dessa hipótese é defendida, por exemplo, por Hawkins (2000), a partir da análise da ordenação de sintagmas preposicionais no inglês escrito. O autor coloca em causa o princípio MLT, sustentando que as alternativas de linearização das categorias de tempo, modo e lugar são motivadas por outros fatores, tais como relações de dependência sintática entre o verbo e o Sprep, o significado do circunstancial e, sobretudo, o peso e a complexidade dos sintagmas preposicionais. Para o autor, a ordenação de constituintes oracionais opera no sentido de garantir um processamento mais rápido e eficiente, o que pode ser assegurado por um princípio segundo o qual "categorias e sintagmas menores precedem os maiores" (HAWKINS, 2003, p.232).

O poder explicativo das hipóteses de centralidade semântica e de peso final é mensurado através da análise de uma subamostra de 86 orações com dois ou mais sintagmas preposicionais em posição pós-verbal. Em função de algumas limitações da amostra, em que não foi atestada a coocorrência dos três circunstanciais na mesma oração, a hipótese foi ligeiramente reformulada. Se correta, a hipótese MLT permite prever que, nas orações com dois circunstanciais, predominem as seguintes formas de sequenciação: Sprep de modo - Sprep de tempo, Sprep de lugar - Sprep de tempo. A distribuição das formas de sequenciação encontradas (gráficos 3 e 4), apontam, no entanto, em direção contrária.

Hawkins (2000) contesta a universalidade de tal sequenciação, com o argumento de que, em línguas do tipo verbo final, essa ordem se inverte para tempo-lugar-modo. 
Gráfico 3 - Sequenciação nas orações com tempo e lugar

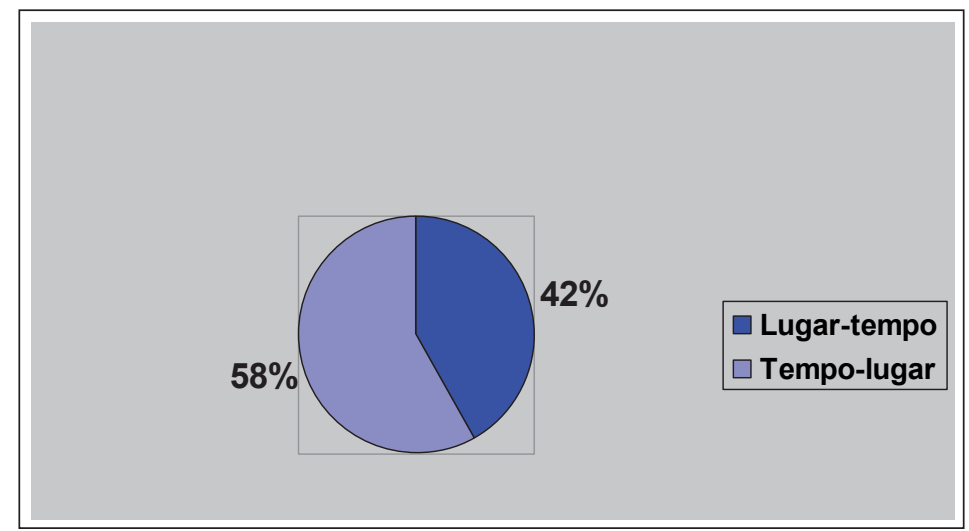

Fonte: elaboração própria.

Gráfico 4 - Sequenciação nas orações com tempo e modo

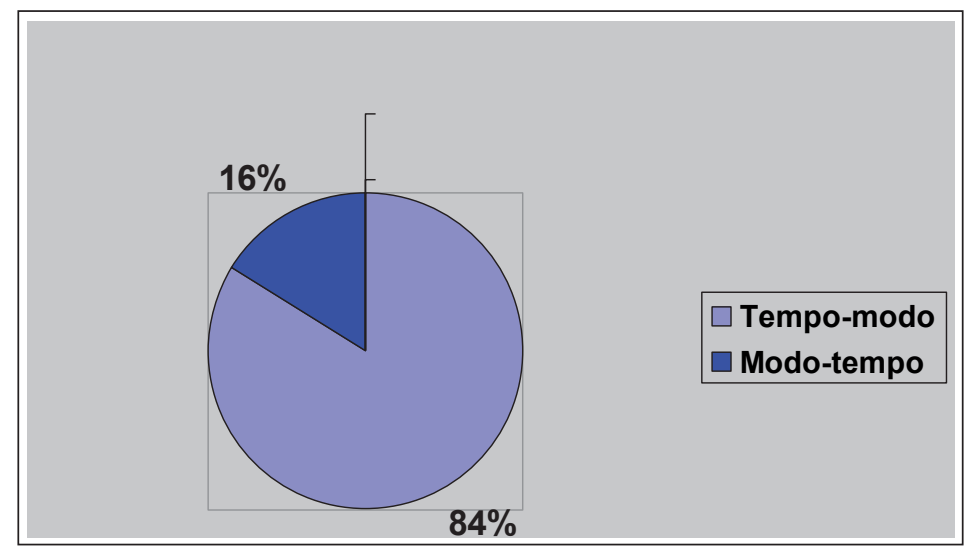

Fonte: elaboração própria.

Tanto na combinação com a categoria de lugar (81 dados) como na combinação com a categoria de modo (5 dados), é o Sprep de tempo que se situa na proximidade do núcleo verbal. Apesar de uma acentuada variabilidade, a sequenciação tempo-lugar é mais frequente (58\%) do que a sequenciação lugartempo (42\%) e a sequenciação tempo-modo predomina nitidamente sobre modotempo (16\%). Apesar do reduzido número de coocorrências tempo e modo, essa distribuição permite colocar em causa o princípio de centralidade semântica e, consequentemente, um pressuposto de ordenação icônica, visto que as categorias consideradas mais centrais (modo e lugar) tendem a se distanciar do núcleo verbal. Em muitos pontos, essa tendência é similar à que se observa na escrita, em que, de acordo com Paiva (2008b), atesta-se igualmente a predominância de 
sequências tempo-lugar e tempo-modo. Uma evidência mais forte é encontrada nas orações com as três categorias, em que é nítida a predominância de sequências tempo-modo-lugar, como em "O corpo da professora foi encontrado na manhã de segunda-feira ${ }^{9}$, COM MARCAS DE TIROS, em Campo Grande", um exemplo extraído da escrita jornalística.

Outra contraevidência, ainda que mais indireta, permite relativizar o efeito da centralidade da categoria semântica sobre a ordenação de Spreps temporais. Embora raramente, dois constituintes satélites, em especial de tempo e de lugar, podem se antepor ao núcleo verbal, sobretudo na margem esquerda da oração. Nesse caso, instancia-se mais frequentemente a sequenciação tempo-lugar, como no exemplo (19):

(19) “Um dia, na festa, a gente se encontramos". - Fala, Amostra Censo, fal. 02.

A tendência destacada acima alinha-se com a posição, sustentada por Hawkins (2000), de que um princípio baseado em uma hierarquia de centralidade semântica do adjunto adverbial, embora pareça uma generalização válida, prevê apenas uma parte limitada dos dados. Uma explicação mais adequada da distribuição mostrada nos gráficos 3 e 4 tem de considerar a possível correlação entre a sequenciação relativa das categorias de tempo, modo e lugar e as restrições impostas pelo peso dos sintagmas preposicionais que as codificam. Podemos pressupor que os circunstanciais mais leves tendem a se situar na adjacência do verbo, e os mais pesados na periferia direita da oração. Para verificar essa hipótese, procedemos a uma reanálise que mensura o peso/extensão dos dois circunstanciais pós-verbais, considerando cinco possibilidades: circunstanciais da mesma extensão, tempo > lugar, lugar > tempo, tempo > modo, modo > tempo. As conclusões que se podem extrair da tabela 3 validam a hipótese colocada.

9 Exemplo extraído da Amostra de textos midiáticos (Reportagem, Jornal Povo, 07-01-04) do Peul. 
Tabela 3 - Extensão e ordem relativa dos circunstanciais de tempo, modo e lugar

\begin{tabular}{lccc}
\hline \multicolumn{4}{c}{ Orações com circunstanciais de tempo e de lugar } \\
\hline & TL & LT & Total \\
Mesma extensão & 11 & 7 & 18 \\
& $61 \%$ & $39 \%$ & 38 \\
Lugar > tempo & 27 & 11 & 25 \\
& $71 \%$ & $29 \%$ & \\
Tempo > lugar & 9 & 16 & \\
\hline Orações com circunstanciais de tempo e de modo \\
\hline \multirow{2}{*}{ Mesma extensão } & TM & MT \\
& $2 / 5=40 \%$ & $1 / 1=100 \%$ & \\
tempo>modo & $3 / 5=60 \%$ & \\
\hline
\end{tabular}

Fonte: elaboração própria

Nas orações em que coocorrem circunstanciais temporais e locativos, é transparente a correlação entre a posição relativa do Sprep temporal e sua extensão: se o circunstancial locativo é mais extenso do que o temporal, instanciase predominantemente a ordenação tempo-lugar (71\%); ao contrário, se o circunstancial temporal é o constituinte mais pesado, predomina a sequenciação lugar-tempo. As duas sequenciações são, portanto, alternativas que resultam da mesma restrição de que o constituinte mais extenso, mais pesado ocupe a periferia direita da oração como ilustram os exemplos (20) e (21):

(20) "Que ficou quatro ano em Garfanha de Nazaré." - Fala, Amostra Censo 1980, fal. 07.

(21) "Eu fui trazer essa garota minha aqui embaixo depois de uma festinha." Fala, Amostra Censo, fal. 02.

Os casos em que o temporal é um advérbio (uma só palavra) corroboram o efeito positivo da extensão na sequenciação relativa dos circunstanciais pósverbais. Num total de 23 orações em que coexistem um advérbio temporal e um Sprep locativo, tende a predominar a sequenciação tempo-lugar (67\% ). Entretanto, essa ordem se inverte (lugar-tempo), nos casos em que o circunstancial locativo 
é uma proforma adverbial, elemento leve de uma ou duas sílabas apenas, como no exemplo (22):

(22) " [...] que ele ficou de chegar lá essa semana." (Fala, Amostra Censo 1980, fal. 47)

Uma outra contra-evidência à hipótese de controle da sequenciação pela centralidade da categoria semântica codificada pelo sPrep pode ser encontrada nos exemplos em que o princípio de extensão não permite nenhuma previsão, ou seja, aqueles em que os dois circunstanciais possuem a mesma extensão. Apesar da considerável alternância entre as ordenações tempo-lugar e lugartempo, observa-se predominância da primeira (61\%). À inversão da ordem, como no exemplo a seguir,

(22) "Eu morei em Laranjeiras alguns anos." - Fala, Amostra Censo, fal. 5.

Subjazem outras restrições, em especial da que envolve as relações de dependência sintática. Nos casos em que o circunstancial locativo integra a grade argumental do verbo com que se liga, como em (22), a proximidade entre ele e o núcleo verbal decorre muito mais de um princípio de integração (GIVÓN, 2001), ou de inerência (SHANNON; COFFEY, 2004) do que da centralidade da categoria de lugar. Se o constituinte adverbial se liga a um verbo que requer complemento com o traço [+locativo], ele precede os constituintes que funcionam como satélites do verbo, como já discutido a respeito das orações com um único circunstancial. Essa restrição explicaria determinadas infrações ao princípio end weight, ou seja, casos em que se o circunstancial locativo, embora mais extenso do que o circunstancial temporal o antecede na cadeia sintagmática, como em (24):

(22) "Falo: bom, vou lá no morro do Salgueiro hoje." - fal. 42.

A estreita dependência sintático-semântica entre o verbo ir e o complemento locativo que o segue, leva o circunstancial temporal hoje a ocupar uma posição reservada, via de regra, a constituintes mais extensos. Evidentemente, esses fatos permitem suspeitar de que o princípio de inerência, se superponha ou mesmo sobrepuje um princípio como peso final.

Uma análise mais localizada nas orações que contêm um verbo cuja grade argumental requer um complemento com o traço [+ locativo] reforça a conclusão de que o princípio ligado ao peso dos constituintes explica uma quantidade maior da variação. No total de 86 orações com constituintes adverbiais na margem direita, 50 possuem núcleos verbais como ir, morar, ficar (na indicação de posição) aos quais se aplica bastante bem as previsões de um princípio de inerência. Em 80\% desses casos (40 orações), o locativo precede o temporal, e, em apenas 
20\%, verifica-se a sequenciação tempo-lugar. Essa distribuição, aparentemente favorável a uma interpretação em termos de inerência, fica comprometida, no entanto, pelo fato de que, em mais da metade dos casos (22/40=55\%), o locativo corresponde a um advérbio leve como lá ou aqui, levando a crer que, nesse caso, a extensão dos constituintes presentes na oração seja mais decisiva do que a exigência de proximidade entre o verbo e seu complemento.

Uma análise estatística mais fina das orações em que coocorrem temporais e locativos ${ }^{10}$ permite afirmar com maior segurança que o princípio peso final explica de forma mais generalizante a sequenciação de sintagmas preposicionais circunstanciais em posição pós-verbal. Tomando como valor de aplicação as possibilidades de sequenciação tempo-lugar e lugar-tempo, mensuramos o efeito da variável extensão e da variável papel sintático do circunstancial locativo, traduzido em termos da oposição +argumental/-argumental. O grupo de fatores extensão é selecionado como estatiscatimente relevante no primeiro nível com significância 0,000. ${ }^{11}$ A função +/- argumental do Sprep locativo, ao contrário, é rejeitada como não significativa.

Pode-se afirmar, portanto, que tanto um princípio de iconicidade como um princípio de coesão ficam minimizados pelas restrições decorrentes do peso dos sintagmas preposicionais.

\section{Considerações finais}

Ao longo deste artigo, apresentamos, através da análise de dados do português falado, evidências de que a posição variável de constituintes oracionais sofre restrições do princípio peso final. Focalizando a ordenação dos sintagmas preposicionais temporais, depreendemos tendências que evidenciam a ação de um princípio mais geral que associa a margem direita da oração a constituintes mais extensos ou mais pesados. A generalidade desse princípio se confirmou tanto nas orações com um único circunstancial, principalmente no que se refere aos Spreps temporais mais leves, como nas orações em que o temporal coocorre com circunstanciais de lugar e de modo. Nesse último caso, o princípio relacionado à extensão dos constituintes explica, ainda, a forma como se sequenciam diferentes categorias semânticas circunstanciais em posição pós-verbal.

A importância da extensão de cada um dos Spreps na sua ordenação relativa fornece argumentos contrários à hipótese de sequenciação MLT (modo-lugar-

10 Os dados foram submetidos a uma análise multivariacional realizada através dos programas GoldVarb2001 que corrige as médias percentuais, atribuindo pesos relativos aos fatores considerados e identifica os grupos de fatores mais relevantes para a ocorrência de uma dada variante.

11 Os valores de peso relativo obtidos para os fatores do grupo extensão são: mesma extensão = 0,53, tempo > lugar $=0,82$ e lugar $>$ tempo $=0,37$. 
tempo), baseada no pressuposto de que categorias semânticas mais centrais tendem a se posicionar na adjacência do verbo. Na modalidade falada do português brasileiro, mais frequentemente a categoria de tempo antecede tanto a de lugar como a de modo. Há, portanto, evidências que contrariam um pressuposto de ordenação icônica segundo o qual a distância do Sprep em relação ao verbo refletiria o significado codificado pelo circunstancial.

Restrições de natureza sintática, como as previstas pelo Princípio de Inerência (ou Princípio de Coesão) são igualmente sobrepujadas pelo princípio de extensão, mostrando que a maior adjacência entre o núcleo verbal e locativos argumentais envolve igualmente restrições ligadas à extensão. Assim tudo indica que a generalização mais correta é a de que Spreps temporais precedem Spreps de lugar ou de modo quando essas categorias são codificadas por sintagmas preposicionais mais extensos, mais pesados. Nesse sentido, a ordenação relativa das categorias circunstanciais de lugar, tempo e modo se alinha a outros fenômenos de ordenação de constituintes e é independentemente motivada.

Algumas questões restam, no entanto, em aberto e merecem análises futuras. A primeira delas diz respeito à possibilidade de generalizar o princípio de extensão para a modalidade escrita. Como já mostrou Paiva (2008b), a partir da análise de textos jornalísticos, o efeito do princípio peso final opera na sequenciação relativa de Spreps temporais de forma semelhante à que se atestou aqui para a modalidade falada. No entanto Paiva et al. (2009) destacam diferenças relevantes na forma como esse princípio atua nas modalidades falada e escrita, quando se consideram apenas as orações com um único circunstancial. As evidências sugerem, portanto, que restrições impostas pelo peso dos circunstanciais temporais são mais decisivas na fala do que na escrita. Resta o problema de explicar essa diferenças. Seguindo a posição de Hawkins (2000), podemos dizer que as próprias características da modalidade falada, como o menor monitoramento, podem torná-la mais propensa a ordenações que respeitam sequências na forma de constituintes mais leves para constituintes mais pesados. A extensão média das orações na modalidade oral é significativamente menor do que a que se observa na escrita, o que pode igualmente favorecer menor número de infrações desse princípio.

A segunda questão diz respeito à própria natureza do princípio de extensão. De forma geral, a tendência de que constituintes menores precedem constituintes mais extenos é interpretada em termos de minimização do custo de processamento da linguagem. O reconhecimento da estrutura de uma frase requer várias decisões simultâneas tanto no nível sintático como no nível semântico. É preferível que essas decisões sejam eficientes, tomadas no menor domínio possível e cadeias linguísticas na forma de constituintes menores para constituintes maiores são, em princípio, mais eficientes. Um ponto central dessa perspectiva é a de 
definir se essa preferência de processamento deve ser entendida em termos de reconhecimento ou de produção da linguagem. Se, por exemplo, para Haiman (2000), ela está relacionada à forma de reconhecimento, para outros, como Wasow (1997), ela poderia se aplicar igualmente à produção. Estudos mais controlados sobre outros fenômenos de ordenação de constituintes podem contribuir para esclarecer esse aspecto.

PAIVA, M. C. Position constraints of temporal prepositional phrases in speech. Alfa, Araraquara, v.56, n.1, p.29-53, 2012.

- ABSTRACT: A number of functionalist studies on word order attest the importance of the end-weight principle, according to which heavier phrasal constituents tend to be places in sentence final position. In this paper we show some evidence that this principle can provide a straightforward account of the variable position of temporal Prepositional Phrases (PP) in spoken Brazilian Portuguese. The order of such constituents is analyzed in two ways: first, we consider sentences that contain only one temporal PP in different positions (initial, medial, and final); second, we extend the analysis to sentences containing time, manner, and place adverbials in post-verbal position. By means of a quantitative analysis, we verify the correlation between the length of the temporal PP and its position in the sentence. The results show that the constraints imposed by the end-weight principle are attestable particularly in sentences where the temporal PP Co-occur with other adverbials, mainly place and manner adverbials, and supersede the semantic and syntactic ones.

- KEYWORDS: Temporal PPS. Position. Variation. Weight.

\section{REFERÊNCIAS}

ABEILLÉ, A.; GODARD, D. La legéreté en français comme déficience de mobilité. Linguisticae Investigationes, Amsterdam, n.29, p.11-24, 2006.

ANDRADE, Q. P. Ordenação das locuções adverbiais de tempo em editoriais. 2005. 157p. Dissertação (Mestrado em Linguística) - Faculdade de Letras, Universidade Federal do Rio de Janeiro, Rio de Janeiro, 2005.

BOISSON, C. Hiérarchie universelle des spécifications de temps, de lieu et de manière. Confluents,Lyon, n.7, p.69-124, 1981.

BRASIL, A. V. Ordenação de circunstanciais em PB e PE. 2005. 180f. Tese (Doutorado em Linguística) - Faculdade de Letras, Universidade Federal do Rio de Janeiro, Rio de Janeiro, 2005.

BYBEE, J. Diagrammatic iconicity in stem-inflections relations. In: HAIMAN, J. (Ed.). Iconicity in syntax. Amsterdam: John Benjamins, 1985. p.11-48.

CEZÁRIO, M. M.; SÁ, E. C. I. de.; COSTA, J. O. Ordenação de adverbiais temporais ou aspectuais. Transformar, Itaperuna, n.1, p.189-203, 2005. 
CEZÁRIO, M. M.; ANDRADE, Q. P.; FREITAS, E. V. P. Ordenação de adverbiais temporais e aspectuais. In: HENRIQUES, C. C.; SIMÕES, D. (Org.). Língua portuguesa: reflexões sobre descrição, pesquisa e ensino. Rio de Janeiro: Europa, 2005. p.212-218.

CEZÁRIO, M. M. et al. Ordenação de advérbios em textos religiosos. Matraga, Rio de Janeiro, n.16, p.177-201, 2004.

COSTA, J. A multifactorial approach to adverbial placement: assumptions, facts and problems. Lingua, [S.l.], n.114, p.711-753, 2004.

CROFT,W. Typology and universals. Cambridge: Cambridge University Press, 1990.

CUNHA, C. A nova gramática do português contemporâneo. 3. ed. Rio de Janeiro: Nova Fronteira, 1976.

FREITAS, M. A. Adjuntos e adjunções em fronteiras de constituintes. 2001. 235p. Tese (Doutorado em Linguística) - Instituto de Estudos da Linguagem, Universidade Estadual de Campinas, Campinas, 2001.

GIVÖN, T. Syntax: an introduction. Amsterdam: John Benjamins, 2001. v.1.

Functionalism and grammar. Amsterdam: John Benjamins, 1995.

GOMES, D. K. A ordem dos circunstanciais temporais e locativos em cartas do séc. XVIII e XIX. 2005. 130p. Dissertação (Mestrado em Língua Portuguesa) Faculdade de Letras, Universidade Federal do Rio de Janeiro, Rio de Janeiro, 2006.

GRIES, S. T. Multifactorial analysis in corpus linguistics: a study of particle placement. New York: Continuum International Publishing Group Ltd, 2003.

HAIMAN, J. Iconicity in syntax. In: (Ed.). Iconicity in syntax. Amsterdam: John Benjamins, 2000. p.187-219.

Natural syntax. Cambridge: Cambridge University Press, 1985.

HAWKINS, J. A. Efficiency and complexity in grammars: three general principles. In: MOORE, J.; POLINSKY, M. (Ed.). The nature of explanation in linguistic theory. Stanford: SLI Publications, 2003. p.121-152.

Why are categories adjacent? Journal of Linguistics, Cambridge, n.37, p.1-34, 2001.

The relative order of prepositional phrases in English: Going beyond manner-place-time. Language Variation and Change, Cambridge, n.11, p.231266, 2000. 
HAWKINS, J. A. Some issues in a performance theory of word order. In: SIEWIERSKA, A. (Org.). Constituent order in the languages of Europe. Berlim: Mouton de Gruyter, 1998. p.729-781.

. A performance theory of order and constituency. Cambridge: Cambridge University Press, 1994.

LESSA, M. M. Ordenação de circunstanciais temporais na escrita:uma comparação entre português e inglês. 2007. 97p. Dissertação (Mestrado em Linguística) Faculdade de Letras, Universidade Federal do Rio de Janeiro, Rio de Janeiro, 2007.

LOHSE, B.; HAWKINS, J.; WASOW,T. Processing domains in English verb-particle constructions. Language, Baltimore, v.80, n.2, p.238-261, 2004.

MACEDO A. M. N. D.; SANTANCHÉ, L. M. Reflexões sobre a sintaxe dos advérbios. Revista de Estudos Linguísticos e Literários, Ondina, v.1, n.21-22, p.15-38, 1998.

MARTELOTTA, M. E. T. Os circunstanciadores temporais e sua ordenação: uma visão funcional. 1994. 242p. Tese (Doutorado em Linguística) - Faculdade de Letras, Universidade Federal do Rio de Janeiro, Rio de Janeiro, 1994.

MARTELOTTA, M. E. T.; VLCEK, N. Advérbios qualitativos em -mente em cartas de jornais do século XIX. Linguística, Rio de Janeiro, n.2, p.5-21, 2007.

MORAES PINTO, D. C. de. Os advérbios qualitativos e modalizadores em -mente e sua ordenação: uma abordagem histórica. 2002. 187p. Dissertação (Mestrado em Linguística) - Faculdade de Letras, Universidade Federal do Rio de Janeiro, Rio de Janeiro, 2002.

NIV, M. Right association revisited. In: MEETING OF THE ASSOCIATION FOR COMPUTACIONAL LINGUISTICS, 30., 1992, Newark. Proceedings... Newark: Association for Computational Linguistics, 1992. p.285-297.

OLIVEIRA, M. R. Advérbios locativos na modalidade escrita do português em perspectiva histórica. In: CHRISTIANO, M. E. et al. (Org). Funcionalismo e gramaticalização: teoria, análise, ensino. João Pessoa: Ideia, 2004. p.131-152.

PAGOTTO, E. A posição dos advérbios, Florianópolis: [s.n., 199-]. Mimeografado.

PAIVA, M. C. de. Ordem não marcada de circunstanciais locativos e temporais. In:VOTRE, S.; RONCARATI, C. (Org.). Anthony Naro e a linguística no Brasil: uma homenagem acadêmica. Rio de Janeiro: 7 Letras, 2008a. p.254-264.

A ordem de circunstanciais no português brasileiro escrito. Diacrítica, Braga, v.22, n.1, p.73-91, 2008b. 
. A ordem não marcada dos circunstanciais locativos. In: LINS, M. P. P.; YAKOVENCO, L. (Org.). Caminhos em linguística. Vitória: NUPLES/DLL/UFES, 2002. p.16-34.

PAIVA, M. C. de et al. Extensão e posição de circunstanciais temporais. Cadernos do CNLF, Rio de Janeiro, v.13, n.4, p.1880-1891, 2009.

Padrão não marcado de ordenação de circunstancias temporais: regularidades e divergências entre fala e escrita. Linguística, Rio de Janeiro, v.1, n.3, p.69-88, 2007.

PEUL. Programa de Estudos do Uso da Língua: banco de dados. Disponível em: $<$ http://www.letras.ufrj.br/peul>. Acesso em: 20 out. 2011.

QUIRK, R. et al. A comprehensive grammar of the English language. London: Longman, 1985.

SÁ, E. C. I. de. Ordenação de locuções de tempo e aspecto em textos jornalísticos: uma abordagem funcionalista. 2009. 110p. Dissertação (Mestrado em Linguística) Faculdade de Letras, Universidade Federal do Rio de Janeiro, Rio de Janeiro, 2009.

SHANNON, T. F; COFFEY, M. P. The Janus-faced order of adverbials in Dutch and English. In: SHANNON, T. (Ed.). Janus at the milennium: perspectives on time in the culture of the low countries. Maryland: University Press of America, 2004. p.245-264.

SHAER, B. Left/right contrasts among English temporal adverbs. In: AUSTIN, J. R.; ENGELBERG, S.; RAUH, G. Adverbials: the interplay between meaning, context, and syntactic structure. Amsterdam: John Benjamins, 2004. p.289-332.

SIEWIERSKA, A. Syntactic eight vs information structure and word order variation in Polish. Linguistics, Cambridge, n.29, p.233-265, 1993.

TARALLO, F. et al. Preenchimentos em fronteiras de constituintes. In: ILARI, R. Gramática do português falado. 2.ed. Campinas: Ed. da UNICAMP, 1993. v.2. p.315-356.

TOMLIN, R. Basic word order: functional principles. London: Routledge: CroonHelm, 1986.

VOTRE, S. J.; SANTOS, E. Colocação do advérbio na fala e na escrita: uma análise sociolinguística. 1984. Relatório final do projeto Análise linguístico-pedagógica das diferenças entre fala e escrita em alunos do $1^{\circ}$ grau, Universidade Gama Filho, Rio de Janeiro, 1984.

WASOW, T. Postverbal behavior. Stanford: CSLI Publications, 2002. 
Remarks on grammatical weight. Language Variation and Change, Cambridge, n.9, p.81-105, 1997.

WASOW, T.; ARNOLD, J. Post-verbal constituent ordering in English. In: ROHDENBURG G.; MONDORF, G. (Ed.). Determinants of grammatical variation in English. London: Mouton de Gruyter, 2003. p.119-154.

Recebido em junho de 2011.

Aprovado em julho de 2011. 